\title{
A forgotten 19th century surgeon: Richard Anthony Stafford (1797-1854), FRCS
}

\author{
Avi Ohry ${ }^{1,2} \cdot$ Waghi S El Masri ${ }^{3,4,5}$
}

Received: 4 June 2017 / Revised: 1 August 2017 / Accepted: 20 August 2017

(C) International Spinal Cord Society 2017

\section{Life Story-part 1}

Richard Anthony Stafford (1797-1854), was born at Cropredy, Oxfordshire, the third son of Egerton Stafford (1763/ 4-1843), vicar of Chalcombe and rector of Thenford in Northamptonshire, and his wife, Mary Lucy, née Wykeham (1769/70-1840) [1]. He was baptized at St Mary's, Witney. One of his mother's ancestors was William of Wykeham (1320-1404) the Bishop of Winchester and Chancellor of England. Stafford was educated at Tamworth and was then apprenticed to two famous surgeons of Cirencester: William Lawrence, (the father of the famous surgeon Sir William Lawrence, Fellow of the Royal College of Surgeons, Fellow of the Royal Society (1783-1867), who became President of the Royal College of Surgeons of London, and Surgeon to the Queen); and Charles Warner (https://www.victoria countyhistory.ac.uk/sites/default/files/work-in-progress/vch_ cirencester_workhouse_v2.5_0.pdf). Stafford moved to London in 1820 and entered St. Bartholomew's Hospital and became assistant/student of John Abernethy (1764-1831), the founder of the medical school of St Bartholomew's, held the office of assistant-surgeon for 28 years, till, "in 1815, he was elected principal surgeon. He had before that time been appointed lecturer in anatomy to the RCS (1814). Abernethy was not a great operator, though his name is associated with the treatment of aneurysm by ligature of the external iliac artery" (https://en.wikipedia. org/wiki/John_Abernethy_(surgeon)). Abernethy appointed

$\bowtie$ Avi Ohry

aohry@ post.tau.ac.il

1 Faculty of Medicine, Tel Aviv University, Tel Aviv, Israel

2 Reuth Rehabilitation and Medical Center, Tel Aviv, Israel

3 Keele University, Keele, Newcastle, UK

4 Hunters Moor Neurorehabilitation Centre, Birmingham, UK

5 The Robert Jones and Agnes Hunt Orthopaedic Hospital, Oswestry, Gobowen, UK
Stafford as his house surgeon from 1823 to 1824. Stafford was admitted as a member of the Royal College of Surgeons in 1824. Stafford returned from 1 year stay in Paris to London in 1826 and began to work as a surgeon. The Jacksonian prize [2] was awarded to him for his work: "On Spina Bifida, and Injuries and Diseases of the Spine and the Medulla Spinalis".

\section{The Jacksonian prize}

"The Jacksonian Prize was founded in 1800 by Mr. Samuel Jackson, FRS, Member of the Royal Colleges of Surgeons of Great Britain and Ireland (MRCS), as an annual prize for a dissertation on a practical subject in surgery. The prize was awarded annually to a Fellow or Member of the College or a Fellow in Dental Surgery of the College, with an established record in a particular field of surgery, and who had made a significant contribution to the advancement of surgery." [3-5].

The Jacksonian Prize was created in the year in which the RCS in London received its Royal Charter- from money provided by Samuel Jackson (1798), MRCS (1787). Mr Jackson (died in 1825) was born as Samuel Orange. He took his fatherin-law name. He was pupil of Mr. Henry Cline (1750-1827) and/or Sir William Blizard (1743-1835) [6]. Cline had performed the first laminectomy for spinal cord injury, Sir Astley Cooper (1768-1841) supported the idea of this operation, while Charles Bell (1774-1842) opposed this idea.

\section{Life Story-part 2}

In 1831, Stafford was elected senior surgeon to the St Marylebone parish infirmary and appointed surgeonextraordinary to the duke of Cambridge. 'St. Charles' Hospital was built as St. Marylebone Infirmary situated in the Ladbroke Grove area of North Kensington. The hospital was opened by the Prince and Princess of Wales in 1881. Its 
name was changed to St. Charles' Hospital when it was transferred from St. Marylebone Board of Guardians to the London County Council in 1930. In 1948 it became part of the National Health Service and came under the control of the North West Metropolitan Regional Hospital Board and the Paddington Group Hospital Management Committee. It now forms part of the Paddington and North Kensington District Health Authority." (http://discovery.nationalarchives. gov.uk/details/r/5bfad71a-85f5-4bf8-a42a-07141e1fcc34).

In $1843, \mathrm{He}$ was elected one of the first fellows of the Royal College of Surgeons. In 1848, he became a member for a short time (due to his ill-health) of its council. He was too ill to deliver his Hunterian oration in 1848 . He never married, and died at 28 Old Burlington Street, London, aged 56, and was buried in Kensal Green cemetery.

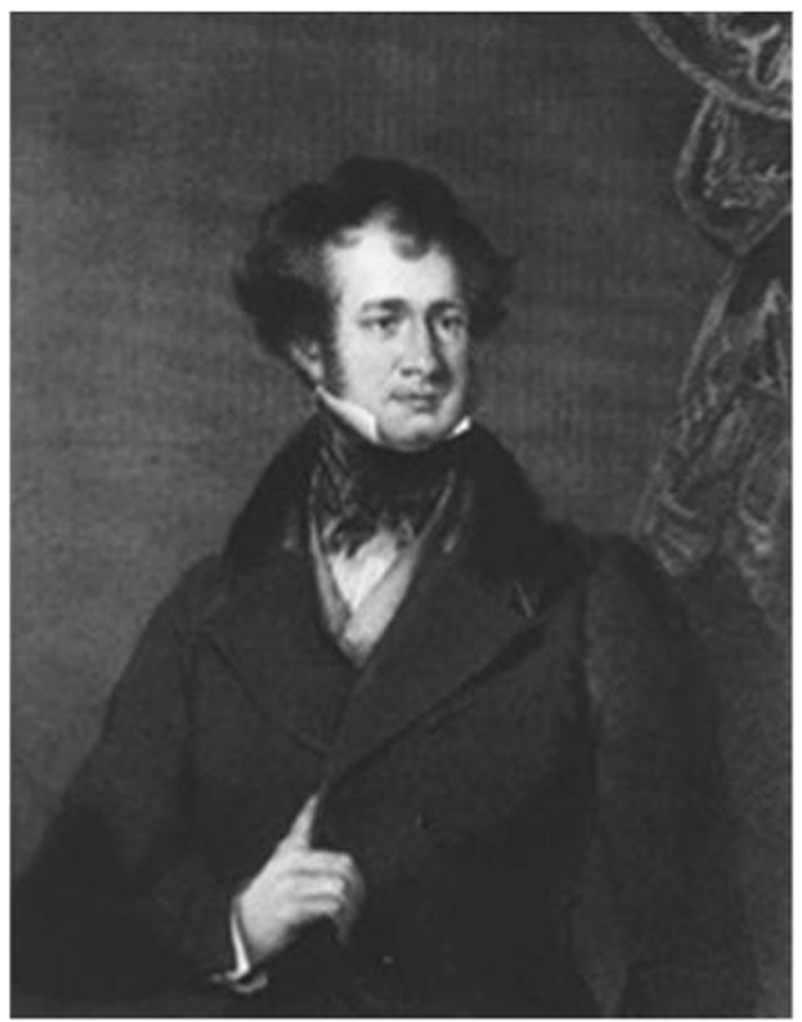

(https://collections.nlm.nih.gov/catalog/nlm:nlmuid101429415-img; picture of RA Stafford in 1839. There is a half-length portrait of Stafford, painted by W. Salter and engraved by J. Cochran. A copy of the engraving is prefixed to Pettigrew's memoir. [Pettigrew's Medical Portrait Gallery, vol. iv.; Lancet, 1854, i. 148; Medical Times and Gazette, 1854, I. 100.])
The "anon" reviewer of Stafford's work on Spinal injuries:

Along 24 pages, Stafford's "Treatise on The Injuries, The diseases, and The Distortions of The spine" (https://www. google.co.uk/search?tbm $=$ bks\&hl $=$ en $\& \mathrm{q}=\mathrm{RA}+$ stafford + surgeon) [7], is critically discussed [8]:

\section{A Treatise on the Injuries, the Diseases, and the Distor- tions of the SpINe; founded on aN Essay to which the Jacksonian Prize, for the Year 1826, was adjudged by the Royal College of Surgeons. By $\boldsymbol{R}$. A. Stafford, Surgeon to the St. Mary-le-bone Infirmary, \&c. Octavo, pp. 302.- London, 1832.}

Apparently, the unknown writer criticized the RCS decision to grant Stafford the Prize; We can presume that the editors asked the writer to give his critical view on Stafford's work:

"Some of these subjects have been copiously discussed of late years, and little novelty can reasonably be expected from a fresh inquirer. Others, for instance the congenital malformations, are not likely, we suspect, to shine with any new or brilliant lights, whoever he may be that ventures to bring them into public view. Perhaps a surgeon of great experience might communicate facts of which we are ignorant, and from them draw conclusions practically useful, respecting the injuries to which the spinal column is liable; but we doubt whether any young man can possibly do what Mr. Stafford confidently promises-compose a work on the diseases and injuries of the spine, which shall not be, for the most part, a compilation. We do not utter this opinion to derogate in the least from Mr. Stafford's merit, but we make the prediction with too firm an expectation, though not with any wish, of seeing it fulfilled. We shall pass without further preface to the examination of the volume ...." Now comes a detailed anatomical discussion on the spinal cord, and descriptions of spina bifida.

\section{Concerning treatment, the unknown writer continued}

"In order to appreciate the value of any proposed plan of treatment, as well as to avoid rash measures on his own part, the surgeon should be aware of the condition and disposition of the spinal nerves in this complaint... The remedial means proposed or adopted by this formidable complaint have been ligature-seton-compression-and puncture with compression. The two former were proposed by Mr. B. Bell and Dessault; there are many obvious and serious objections to their employment. The two latter were recommended by Mr. Abernethy, and have frequently been employed. Compression is a palliative measure, and has proved no more. Puncture, with compression, appears to 
promise rather more, but we must not expect much from any treatment. A short time ago we saw a young girl, apparently, if our memory serves us, some 14 years of age, who had had spina bifida since infancy. The tumor was in the sacral region, about the size of an orange but flatter, with thin but not inflamed parietes. The girl was in good health, though of strumous appearance, and seemed to suffer little inconvenience from the disease. We believe that compression and puncture had been tried, but latterly all applications were abandoned, and the tumor was not on the increase. We shall now mention some cases related by Mr. Stafford, as they will convey more information on such a point than descriptions." ...

As the authors read it today, Stafford himself, described treatment of the "tumor" by repeated punctures. It seems that Stafford used his mentor's methods. The patients he described, were not paralyzed. We all know, that in those days, most of the paraplegics with complete lesion, did not survive long. Guttmann's and others made the breakthrough only in mid 20th century.

The writer of this critical review, concluded:

We have dedicated more space to the consideration of this part of the volume, than practical men might, perhaps, deem necessary. But the nature and treatment of spina bifida are not so well understood as they should be and possibly the information actually obtained is not universally diffused. Any little addition to our knowledge is, therefore, desirable on the one hand, and a free dissemination of it is useful on the other. The following short summary may be added.

The next section of this review is devoted to Stafford's thesis on spinal injuries.

On the Injuries of the Spine.

Much has been said on these injuries by experienced surgeons, and few

in the ordinary pursuits of their profession fail to meet with cases of the kind occasionally. It is incumbent on practitioners to understand their nature and treatment. The chief injuries of the spine are concussionfracture-dislocation.

As we see it today clearly, Stafford classified spinal paralysis as "complete" vs. "incomplete". It is apparent, contrary to the "reviewer", that Stafford's experience included many paralyzed patients. And in Stafford's words:

"The patient immediately after the injury, as in all cases where the nervous system has received a violent shock, becomes almost lifeless-a marble coldness pervades the whole frame, but more particularly the paralysed limbs. He cannot lie in any other position than on hack; - his pulse is weak and faltering; and he is is icnty almost unconthis situation he remains for a few hours, when reaction gradually commences. The warmt of the body returns until it amounts to a state of fever. The pulse rises, becomin waick, hard, and full, the tongue is furred, and great thirst is felt. The patient has more or less pain in the injured part, and sometimes delirium supervenes. If the injury be received high up, there is dyspnoa, in consequence of the muscles of respiration being paralysed, and, as I have before stated, the parts below suffer paralysis, according to where the injury was received.

A further descriptions of sphincters' paralysis is followed. The problem of "spinal dislocation" was discussed with citations from the works of Sir Astley Cooper and J-L
Petit. Stafford also discussed thoroughly the inter-vertebral disc problems and vertebral diseases.

The "anon" reviewer of Stafford's thesis, wrote that:

\begin{abstract}
The succeeding chapters from the fifth to the tenth, including both, are occupied with the consideration of the diseases of the vertebral bones and intervertebral cartilages. After the many excellent monographs which have been published, it cannot be supposed that Mr. Stafford could offer much novelty on such a subject. He bas not, and all we can do is to select here and there a passage conveying some new view, or interesting fact. We will take the following remarks on the cancellous structure of the spinal bones.
\end{abstract}

In some of his described cases, Stafford did not mentioned their final clinical outcome, but he managed to describe immediate and late complications. The importance of vertebral fixation after trauma was well known to Stafford and other surgeons of his times:

Both of these cases occurred to my own knowledge, and from them it may be seen how necessary it is to keep the spine quite motionless, and more parricularly when the acciden one of the double-inclined plane-beds, upon his back, and hj, hought mored uatil there is aufficient resson to believo the fracture is united " 95 .

Stafford employed 19th century model of treatment for the spinally paralyzed: in the reviewer's words:

"Cupping, leeching, blistering, warm-bath, the catheter, \& c. were the means employed..." By all means, we can presume, that some of these useless (futile) treatments, did not change substantially the poor outcome.

At the end of that review, the author (Stafford) concluded: "We have selected from this work such portions as appeared to offer any novelty, instruction, confirmation, or otherwise of unsettled points. It might be much condensed, and more attention might be paid to its literary composition. We meet with instances of defective grammatical construction, and such vulgarisms as "it stands to reason". Faults of this kind are serious only because remediable with care and circumspection on the part of the author. Mr. Stafford is active, industrious, intelligent, and we wish him all success."

\section{Stafford described the paralytic spinal joints' contractures}

Stafford described the paralytic spinal joints' contractures in cases of cerebral palsy, and spinal injury [9], and how to treat them: "The treatment consisted of local depletion by cupping and leeches over the lumbar region, and along the course of the ischiatic nerve; the exhibition of antimonials, opiates, and aperients; and afterwards the employment of counter-irritants by blisters, tartar emetic ointment, and issues on each side of the spine in the lumbar region.". For the modern reader, these treatments seem to be an absurd. We do not know if any physical (today's physiotherapy) or manual methods were added. If the blame for the joint 
contracture, was put on the nerves, the rational for Stafford's methods seem to be understandable but, alas, futile.

\section{Mr Stafford on Contraction of the Lower Bxtremities}

ART. V.-On Long-continued Contraction of the Lower Evtremities from an affection of the Spine. By R. A. SrafFord, Esq. Surgeon to the St Mary-I,e-Bone Infirmary. 8vo, pp. 26.

IN this tract Mr Stafford gives a particular account of a peculiar rigid, contracted, or inflected condition of the lower extremities, which has been long known to take place in certain stages and forms of spinal disease, and which is more or less familiar to those who have paid much attention to the different stages and forms of spinal disease.

The kind of contraction of which Mr Stafford treats consists in the members being involuntarily and irresistibly inflected on each other by the gradual involuntary and spastic action of the flexor muscles; while the extensors possess no power of again extending them or opposing and withstanding this forcible contraction of the flexor muscles. Thus, the thigh may be inflected on the belly to a greater or less extent; the leg is inflected backward on the thigh, with complete stiffness of the knee-joint; and in some instances the latter inflection is so considerable that the calf of the leg rests on the back part of the thigh; and the heel presses closely on the nates, the foot being turned backwards as represented in the engraving, (Fig. 1.) In order to illustrate the nature of this kind of lesion of the locomotive organs, Mr Stafford details the circumstances of five cases, of four of which we give short abstracts.

CAsz I.-Mary Kean, aged 30, a slightly made girl, of small stature, was admitted in January 1833, into the St Mary-Le-Bone Infirmary, with complete contraction of the right lower extremity, and contraction of the third and little finger of the hand of the same side. She possessed the faculty of feeling in both limbs. But the knee-joint was firmly bent and stiff; the calf of the leg rested on the back part of the thigh; and the heel was closely pressed on the nates, the foot being turned backwards, as represented in the engraving, Fig. 1. She stated that she had been subject to epileptic fits since infancy; that about two years previous to admission she was attacked with violent pain in the lumbar region, pain in the hip and knee, and acute pain alon the course of the ischiatic nerve, with considerable tenderness and increased sensibility of the whole limb. At this period the right lower extremity became gradually but firmly contracted, and the contraction could be by no means prevented. Shortly after the two last fingers of the right hand also became contracted and inflected into the palm of the hand, so as to lie across the index and middle-finger of the same hand. She was admitted into one of the London hospitals, where the symptoms underwent some mitigation, but the limbs remained in the same state.

"When the lower extremities are affected with spasmodic and involuntary inflection, it may be inferred that the membrane of the spinal chord, or the spinal chord itself, or both, are irritated by the early or incipient stage of inflammatory congestion. It is not likely that the stage of inflammation is fully established; and much less likely that it has given rise to new morbid products; because in either case motion would be more completely impaired than it is, and perhaps would be entirely abolished. At least we find that a very small amount of morbid products is quite sufficient to abolish motion and sensation in the lower extremities. This seems to afford the explanation of the phenomena in the first case given by Mr Stafford. Had the spinal chord or its investments been affected with organic changes or morbid products, the limb could never, by any species of treatment, have recovered its faculty of motion. There is every reason to believe, however, from the symptoms, the progress of the case, the effects of the treatment, and its ultimate termination, that the morbid state consisted in irritation of the spinal chord and the roots of the nerves, by the overloaded state of the vessels, either of the membranous coverings, or of the spinal chord itself."....[10] MR STAFFORD'S CASES AND INSTRUMENT.

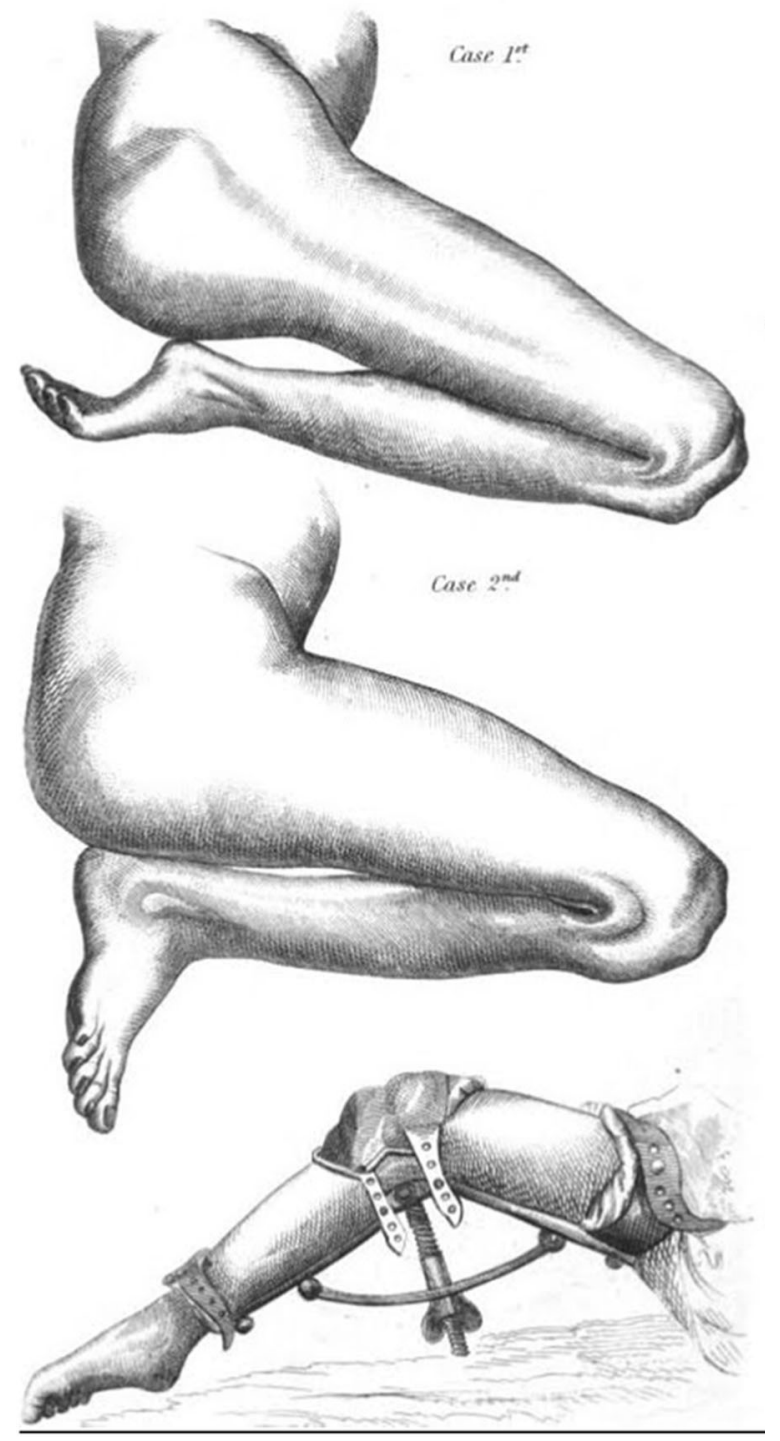

[9]

Was the contracture correction maintained or were there any consequences using this approach? We do not know.

A tenotomy is a surgical act which involves the division of a tendon. It and related procedures are also referred to as tendon release, tendon lengthening, and heel-cord release. 
In 1685 the Dutch surgeon, Isacius Minnius, performed for the first time a corrective surgery for torticollis by tenotomy.

The first who performed this procedure percutaneously were: J-M Delpech (1777-1832) of Montpellier, and G-F Stromeyer (1804-76) of Hanover, who performed tenotomy in Dr. W-J Little's post-poliomyelitic club-foot (1810-94). Little himself became an enthusiastic advocate of this operation. Another description in the same period of Stafford appeared in 1840 [11]:

\begin{abstract}
The sixth patient had paralysis of the right inferior extremity, accompanied by considerable flexion of the leg on the thigh. M. Dural thought it dependerl on contraction of the muscles of the calf, which are also flexors of the thigh. He cut the tendo Achillis, and in six weeks the cure was complete.
\end{abstract}

Stafford's physical method to correct joint contracture (in a paralyzed patient who might developed Complex Regional Pain Syndrome) seemed to be successful. The topics of his other publications $[12,13]$ spanned from the prostate gland, pathological dissection, to brain injury $[14,15]$.

\section{Stafford's absence in historical reviews}

We decided to study Richard Stafford's contributions to medicine and especially to spinal cord injuries, because we discovered that although he wrote extensively on SCI and related topics, he is totally absent and ignored in history of medicine texts. The illustration of the new treatment of joints' contracture seems interesting. His clinical approach and systematic classification sounds modern to us. We relied almost exclusively on an unidentified author who seems to minimize his importance and contributions. It was not a rare phenomenon to find unsigned articles, reviews, or editorials which had appeared in leading journals (as in refs. 2-5).

Stafford is not mentioned in reviews of the history of spinal cord injuries [16-19] or in a basic historical book on orthopaedics [20]. Possibly because he did not add any new insight or introduced revolutionary treatments. He was a devoted surgeon, published books and articles on spinal injuries and other topics, and was an active member of The Royal College of Surgeons of London. We do not know if he got the idea to write his thoughts about spinal injuries from his teachers and mentors, or rather, accumulated clinical experience during his hospitals' work. For sure, he and his generation were witnessed to the Bell/Cooper controversy.

Acknowledgements Our sincere thanks to Ms. Samantha West, Senior Library Assistant. Francis Costello Library, RJAH Orthopaedic Hospital NHS FT, Oswestry, SY10 7AG, and Ms. Heather Edwards, Business Co- ordinator, Midland Centre for Spinal Injuries, RJ \& AH Orthopaedic Hospital, Gobowen, Oswestry, Shrops SY10 7 A

\section{Compliance with ethical standards}

Conflict of interest The authors declare that they have no competing interests.

\section{References}

1. Oxford Dictionary of National Biography. Lancet (4 Feb 1854). TJ Pettigrew. Medical portrait gallery: biographical memoirs of the most celebrated physicians, surgeons ... who have contributed to the advancement of medical science. 4 vols. in 2 [1838-40]. Foster. Alum. Oxon., 1715-1886 [Egerton Stafford]. VG Plarr, Plarr's Lives of the fellows of the Royal College of Surgeons of England, rev. D'A. Power, 2 vols. (1930). PJ Wallis, RV Wallis. Eighteenth century medics, 2nd edn (1988). Witney parish registers, Oxfordshire Family History Society · census returns, 1851 . burials register, All Souls, Kensal Green - private information (2015) [E Reid, Oxfordshire History Centre; H Vivian-Neal, Friends of Kensal Green Cemetery]

2. Anon. The Jacksonian Prize. BMJ. 1899;1:818-820.

3. Anon. The Jacksonian Prize. Ann R Coll Surg Engl. 1976;58:496-497.

4. Anon. The Jacksonian prize. Ann R Coll Surg Engl. 1968; 42:306

5. Anon. The Jacksonian prize- a retrospect. BMJ. 1899;1:818-20.

6. Anon. The Honorary Medal of the College. Ann R Coll Surg Engl. 1949;4:399-400.

7. Stafford RA. A treatise of the injuries, the diseases and distortions of the spine, Vol. 8. Longman's, 1826. https://books.google.co.uk/ books? output $=$ text $\& \mathrm{id}=\mathrm{oBcCAAAAYAAJ} \& \mathrm{dq}=\mathrm{RA}+$ stafford + surgeon\&ots $=\mathrm{BEwICcE} 4 \mathrm{CQ} \& \mathrm{q}=$ Stafford\# $\mathrm{v}=$ onepage $\& \mathrm{q}=$ Stafford $\& \mathrm{f}=$ false.

8. Anon. A treatise of the injuries, the diseases and distortions of the spine. The Medico-Chrurgical Review. 1832;17:1-24

9. Stafford RA. On long contraction of the lower extremities from the affection of the spine. Edinb Med Surg J. 1839;52:532-41. https://books.google.co.uk/books?id=TmRd3LQRwwAC\&pg $=$ PA532\&lpg $=$ PA532\&dq $=$ RA + stafford + surgeon\&source $=$ bl \& ots $=$ PUjXKk-n_p\&sig $=$ dOy3ORHi3me8hWMXtDN2tRmZn5Q $\& \mathrm{hl}=\mathrm{en} \& \mathrm{sa}=\mathrm{X} \& \mathrm{ved}=0 \mathrm{ahUKEwiSkIDdy}$ HRAhUD0RQKHZA NC6cQ6AEIHDAB\# $\mathrm{v}=$ onepage $\& \mathrm{q}=\mathrm{RA} \% 20$ stafford $\%$ 20surgeon $\& \mathrm{f}=$ false.

10. Stafford RA. On the injuries of the spine. Gentlem. Mag. Hist. Rev. 1857;1:85.

11. Anon. In the section of: surgical pathology and therapeutics. Edinb Med Surg J. 1840;53:249.

12. Stafford RH. Concussion of the brain. London Medical Gazette. 1842;30:92. https://books.google.co.uk/books?id=w_9wPUMQkp0C\&pg $=$ PA92\&lpg $=$ PA92 \&dq $=\mathrm{RA}+$ Stafford + surgeon + saint + Marylebone + hospital\&source $=$ bl\&ots $=$ w0ZeOX3Kea\&sig $=$ Cc6FTJLV2EyAgy6Xf-awze3m6Gk\&hl= en\&sa $=X \& v e d=0 a h U K E w j 5$ vumjgfTRAhV

CwBQKHaGsDzwQ6AEIIDAC\#v=onepage $\& \mathrm{q}=\mathrm{RA} \% 20$ Stafford $\% 20$ surgeon $\% 20$ saint $\% 20$ Marylebone $\% 20$ hospital $\& \mathrm{f}=$ true.

13. Owen R. Lectures on the comparative anatomy and physiology of the vertebrate animals, delivered at The Royal College of Surgeons of England in 1844 and 1846. p12. https://books.google.co. $\mathrm{uk} / \mathrm{books} ? \mathrm{id}=$ olI9AAAAYAAJ $\& \mathrm{pg}=\mathrm{PT} 12 \& \mathrm{lpg}=\mathrm{PT} 12 \& \mathrm{dq}=$ $\mathrm{RA}+$ stafford + surgeon $\&$ source $=$ bl\&ots $=\mathrm{cIVoBpizKE} \&$ sig $=$ 2N_keQ1fN6R21K0RwBjjBn1YVEg\&hl=en\&sa $=$ X\&ved $=$ 0ahUKEwiLrK78y_HRAhUBbhQKHXcmD1gQ6AEIHjAC\#v= onepage $\& \mathrm{q}=\mathrm{RA} \% 20$ stafford $\% 20$ surgeon $\& \mathrm{f}=$ false

14. Stafford RA. On the treatment of injuries received in dissection. Med Chir Trans. 1837;20:50-77. 
15. Stafford RA. A case of enlargement from melanoid tomour of the prostate gland in a child of five years of age. Edinb Med Surg J. 1840;53:376-8.

16. Ohry A, Ohry-Kossoy K. Spinal cord injuries in the 19th century -background, research and treatment. Supplement to Paraplegia ISSN 0031-1758, Churchill Livingstone: Edinburgh; 1989.

17. Guttmann L. Historical background, chapter 1. In: Spinal Cord Injuries. Oxford: Blackwell Scientific Publications; 1976. p. $1-8$.
18. Ohry A, El Masri WS, Chhabra HS. Spinal Cord Injury Management-historical perspective. In: Chhabra HS (ed.) ISCOS Textbook on Comprehensive Management of Spinal Cord Injuries. India: Wolters Kluwer; 2015. Chapter 1, p. 3-22.

19. Silver JR. History of the Treatment of spinal Injuries. NYC, Boston, London: Kluwer academic and Plenum Publishers; 2003.

20. Bick EM. Source book of Orthopaedics. London: Hafner Publishing Co.; 1968. 